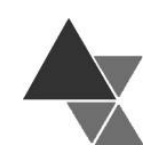

\title{
Biofortificação de alimentos: problema ou solução?
}

\author{
Marina Paraluppi Loureiro ${ }^{1}$, Luana Ribeiro da Cunha ${ }^{2}$, Bruna Thomé Nastaro ${ }^{3}$, \\ Karollyne Yoshioka dos Santos Pereira ${ }^{4}$ e Monalisa de Lima Nepomoceno ${ }^{5}$
}

Uma das estratégias apontadas para o combate aos déficits nutricionais é a biofortificação de alimentos, uma técnica que visa aumentar o teor de nutrientes específicos em alimentos básicos. Entretanto, nos últimos anos, questionamentos acerca de suas potenciais consequências negativas ao meio ambiente e à Segurança Alimentar e Nutricional passaram a ser levantados. Diante do exposto, o presente artigo objetivou realizar um levantamento bibliográfico sobre a biofortificação de alimentos, acerca de suas questões nutricionais, culturais, econômicas e ambientais e suas principais controvérsias, utilizando como ferramenta as bases de dados Scielo, Web of Science, Pub Med, Portal de Periódicos Capes e Science Direct, Biblioteca Digital de Teses e Dissertações da USP e o Google Acadêmico. Embora a biofortificação tenha, em muitos casos, se mostrado um caminho promissor para melhorar os teores de nutrientes e vitaminas nos diversos itens alimentares é verídico afirmar que a mesma apresenta diversos aspectos negativos. Logo, é imprescindível a realização de estudos que visem elucidar seus amplos efeitos, contemplando as esferas econômica, política, social e nutricional. Enquanto isso, estratégias que visem solucionar as principais causas da insegurança alimentar são as mais recomendadas para a solução do problema da fome, seja ela oculta ou crônica.

Palavras-chave: biofortificação de alimentos, segurança alimentar e nutricional, fome oculta, sustentabilidade na alimentação.

\section{Food Biofortification: problem or solution?}

Biofortification is one of the indicated strategies for fighting nutritional deficits, being a technique that aims the increase on the contents of specific nutrients in staple foods. However, there have been questions about the potential negative consequences it brings not only to the environment but also to the Food Security and Nutrition. The present work aimed at a bibliographic survey about biofortification, broaching questions about the nutritional, cultural, economic and environmental aspects related to this theme and the main controversies about it. Scielo, Web of Science, Pub Med, Capes portal of scientific journals, Science Direct, USP Digital Library of Theses and

\footnotetext{
${ }^{1}$ Bacharel em Ciências dos Alimentos. Departamento de Agroindústria, Alimentos e Nutrição, Escola Superior de Agricultura "Luiz de Queiroz" (ESALQ), Universidade de São Paulo (USP). Graduanda em Nutrição, Centro Universitário Claretiano, Rio Claro, SP. Endereço para correspondência: Av. Pádua Dias no 11, CEP: 13418-900, Piracicaba, São Paulo, Brasil.E-mail: marina.p.loureiro@gmail.com

2 Bacharel em Ciências dos Alimentos. Departamento de Agroindústria, Alimentos e Nutrição, Escola Superior de Agricultura "Luiz de Queiroz" (ESALQ), Universidade de São Paulo (USP). Graduanda em Nutrição, Centro Universitário Claretiano, Rio Claro, SP.

${ }^{3}$ Bacharel em Ciências dos Alimentos. Departamento de Agroindústria, Alimentos e Nutrição, Escola Superior de Agricultura "Luiz de Queiroz" (ESALQ), Universidade de São Paulo (USP).

${ }^{4}$ Bacharel em Ciências dos Alimentos. Departamento de Agroindústria, Alimentos e Nutrição, Escola Superior de Agricultura "Luiz de Queiroz" (ESALQ), Universidade de São Paulo (USP).

${ }^{5}$ Bacharel em Ciências dos Alimentos. Departamento de Agroindústria, Alimentos e Nutrição, Escola Superior de Agricultura "Luiz de Queiroz" (ESALQ), Universidade de São Paulo (USP). Analista de Assuntos Regulatórios, Fukuma Advogados \& Consultores Jurídicos.
} 
Dissertations and Google Scholar were the databases used as tools for the work. Although the biofortification has proved to be, in many cases, a promising way to improve the amount of nutrients and vitamins in different types of food, it is truthful to affirm that this alternative also presents negative aspects. Therefore, studies are indispensable to elucidate the diverse effects of biofortification, considering the economic, political, social and nutritional spheres. Meanwhile, strategies that seek to strike the main causes of food insecurity are the best options in order to solve the problem of hunger, being it hidden or chronic.

Keywords: biofortification, food security and nutrition, hidden hunger, food sustainability.

\section{INTRODUÇÃO}

Os alimentos biofortificados foram inicialmente desenvolvidos para combater um problema mundialmente conhecido, denominado fome oculta, que acomete em torno de 2 bilhões de pessoas no mundo. A deficiência de micronutrientes específicos, como zinco, vitamina A e ferro, é considerada um problema de saúde pública, resultando na redução da capacidade de trabalho, distúrbios no sistema imunológico e doenças como a anemia, podendo levar à morte[ ${ }^{[1]}$.

Em decorrência da maior preocupação perante o cenário mundial de desnutrição e crescimento populacional, em 1993 foram iniciados estudos voltados para a área de biofortificação de alimentos, buscando melhorar a qualidade dos itens alimentares obtidos a partir da agricultura, por meio de procedimentos como o melhoramento convencional, emprego de técnicas agronômicas e/ou transgenia/biotecnologia $[2,3,4]$. No Brasil, as pesquisas referentes ao tema biofortificação iniciaram-se no ano de 2003, a partir de uma parceria estabelecida entre o programa HarvestPlus e a Empresa Brasileira de Pesquisa Agropecuária (EMBRAPA) ${ }^{[5]}$

A biofortificação, em geral, baseia-se em um processo de cruzamentos repetidos de plantas da mesma espécie até a obtenção de cultivares mais nutritivos, elevando os teores de nutrientes e vitaminas. Portanto, alimentos biofortificados possuem teores aumentados de determinados micronutrientes quando comparado a um alimento convencional. Esse processo pode ser também denominado de melhoramento genético convencional[6,7].

Desde o seu surgimento, o uso da biofortificação em alimentos foi justificado por seu potencial auxílio no combate às deficiências de micronutrientes, as quais atingem grande parte da população mundial, sendo que, durante anos, houve grande incentivo à produção de alimentos biofortificados. Porém, com o desenvolvimento de uma Política Nacional de Segurança Alimentar e Nutricional (PNSAN), algumas dúvidas em relação aos alimentos biofortificados começaram a ser levantadas [5]. De fato, existem premissas de que alimentos biofortificados poderiam contribuir para $\mathrm{O}$ desenvolvimento da agricultura e para a Segurança Alimentar e Nutricional (SAN). Por outro lado, alguns questionamentos são pertinentes, como o possível risco à agrobiodiversidade e a contaminação de culturas puras pelo uso de sementes biofortificadas, além de outros impactos ambientais de grande magnitude e envolvimento de interesses políticos ${ }^{[]}$.

Face à lacuna de análises e tendo por base as publicações sobre a temática abordada anteriormente, o objetivo principal do presente trabalho foi realizar uma revisão bibliográfica sobre a biofortificação de alimentos e sua contribuição para o alcance da SAN, debatendo aspectos relativos ao panorama nacional da deficiência de micronutrientes, aos tipos de biofortificação empregados, ao uso da biofortificação e às principais controvérsias que tangem o tema apresentado.

\section{METODOLOGIA}

O presente trabalho consistiu em uma revisão de literatura realizado com auxilio de bases de dados bibliográficas. A pesquisa por artigos científicos foi realizada utilizando as seguintes bases: Scielo, Web of Science, Pub Med, Portal de Periódicos Capes e Science Direct. Teses, dissertações e documentos foram obtidos com auxílio da Biblioteca Digital de Teses e Dissertações da USP e do Google Acadêmico 
utilizando os termos "biofortificação", "controvérsias" "segurança alimentar e nutricional" "deficiências de micronutrientes". Foram selecionados somente artigos, teses e documentos publicados em língua portuguesa ou inglesa entre os anos de 2000 e 2017.

\section{RESULTADOS E DISCUSSÃO}

\section{Situação nacional da carência de micronutrientes}

Pesquisas elaboradas no Brasil, com enfoque na alimentação e suas consequências à saúde humana, revelam que, embora prevaleça o problema do sobrepeso e da obesidade, ainda são encontrados, com frequência, distúrbios relacionados à desnutrição e às carências de determinados micronutrientes ${ }^{[8,9]}$.

De acordo com a Rede de Alimentação e Nutrição do Sistema Único de Saúde ${ }^{[10]}$, no mundo, mais de dois bilhões de indivíduos sofrem com as consequências das deficiências de vitamina $A$, ferro, iodo e zinco.

A deficiência de vitamina A consiste em um dos principais problemas relacionados à fome oculta presente em países em desenvolvimento, acometendo, principalmente, grupos populacionais vulneráveis, como crianças, gestantes e lactantes e estando simultaneamente relacionada às condições socioeconômicas do ambiente[11]. Dados reunidos pela Organização Mundial da Saúde (OMS) ${ }^{[1]}$ calculam que, no mundo, cerca de 190 milhões de crianças e bebês convivam com a deficiência da vitamina. Já no Brasil, estima-se que cerca de 2,4 milhões de infantes apresentem o problema ${ }^{[12]}$. A OMS ${ }^{[13]}$ contabiliza, ainda, que aproximadamente 19 milhões de gestantes, principalmente habitantes da África e Sudeste Asiático sejam portadoras de hipovitaminose A e preconiza a utilização de suplementos de vitamina A para estas mulheres, principalmente para aquelas que habitam lugares onde tal deficiência seja considerada um grave problema de saúde pública.

A anemia provocada pela deficiência de ferro (anemia ferropriva) consiste em outro problema relacionado às carências nutricionais presentes na sociedade brasileira, acometendo especialmente as crianças, principalmente aquelas que ainda não completaram 5 anos de idade, as mulheres em idade fértil, as adolescentes do gênero feminino, as gestantes e as nutrizes [14,15]. Dados apresentados pela OMS[16] demonstraram, ainda, que no mundo todo, cerca de 293 milhões de bebês e crianças eram portadores de anemia.

No Brasil, a anemia encontra-se associada às condições socioeconômicas dos indivíduos, trazendo diversas consequências negativas como danos ao crescimento, ao sistema imunológico e ao desenvolvimento cognitivo e da linguagem, além de ocasionar perda de apetite e redução da disposição e da produtividade ${ }^{14]}$. Em território brasileiro, cerca de 5 milhões de crianças de 1 a 4 anos são portadoras de anemia [15]. Além disso, estudos regionais apresentam discrepâncias nos resultados acerca da prevalência da enfermidade, com variações oscilando entre $22,7 \%$ e $77,0 \%$, ocasionadas em virtude das desigualdades socioeconômicas que permeiam o país ${ }^{[15]}$. As principais causas da doença são o baixo consumo de alimentos fontes de ferro, bem como a biodisponibilidade do nutriente em questão, além dos fatores socioeconômicos anteriormente mencionados. Além do mais, a anemia ferropriva não se limita a afetar apenas indivíduos de baixa renda ou que sofrem de desnutrição, porém atinge facilmente grupos populacionais que apresentam crescimento rápido, como as crianças, ou que tenham a demanda por ferro aumentada, como as gestantes ${ }^{[15]}$.

Como principais estratégias de prevenção e tratamento da anemia, o Ministério da Saúde ${ }^{[17]}$ cita a suplementação com medicamentos à base de sais de ferro, o combate às verminoses e doenças de origem infecciosas, o acesso ao tratamento de água e esgoto, a educação alimentar e nutricional, estimulando $\mathrm{O}$ consumo de alimentos ricos em ferro e a adoção de práticas alimentares que visem aumentar a sua biodisponibilidade e a fortificação dos alimentos básicos, especialmente das farinhas de trigo e milho.

A Agência Nacional de Vigilância Sanitária (ANVISA) publicou no Diário Oficial da União, em 17 de abril de 2017, a Resolução RDC no 150[18] que atualiza a RDC no 344 de 2002, estabelecendo os requisitos para o enriquecimento obrigatório de farinhas de trigo e milho com ferro e ácido fólico. Esta resolução contém as quantias mínimas dos respectivos micronutrientes a ser adicionados na farinha para que tal enriquecimento seja efetivo. Assim, as mesmas, após fortificação, devem apresentar teores de ferro entre 4 a $9 \mathrm{mg}$ para cada $100 \mathrm{~g}$ de farinha e teores de ácido fólico 
variando entre $140 \mu \mathrm{g}$ a $220 \mu \mathrm{g}$ para cada $100 \mathrm{~g}$ do alimento, levando em consideração as diretrizes da OMS. É valido ressaltar que, neste regulamento, houve a alteração da lista de compostos fonte de ferro a serem utilizados, sendo permitido somente a adição de sulfato ferroso e fumarato ferroso, bem como suas formas encapsuladas. Além disso, foram alteradas as informações que devem aparecer na rotulagem obrigatória, uma vez que o rótulo precisa ser claro ao consumidor para que este compreenda o objetivo da fortificação do produto, expondo os benefícios de tal enriquecimento e contendo, também, a informação sobre o teor adicionado. Farinhas de milho fabricadas por agricultores familiares, empreendedores familiares rurais, empreendimentos econômicos solidários e microempreendedores individuais estão isentas da obrigatoriedade do enriquecimento, devido a realidade de seus processos produtivos. Também foram excluídas da obrigatoriedade de fortificação as farinhas de biju, farinha de milho flocada ou flocos de milho précozidos, farinha de trigo integral e de trigo durum e farinhas de trigo e de milho contidas em produtos alimentícios importados ${ }^{[18,19]}$.

A Pesquisa Nacional de Demografia e Saúde da Criança e da Mulher (PNDS), realizada em 2006[20], mostrou que cerca de $21 \%$ das crianças eram acometidas pela anemia, enquanto que entre as mulheres não gestantes, 29\% possuíam a doença. Em relação a deficiência de vitamina A cerca de $17 \%$ das crianças e $12 \%$ das não gestantes apresentavam o problema ${ }^{[8,20]}$. É importante ressaltar que a PNDS tem mais de uma década e não houve nenhuma atualização até o presente momento.

O Estudo Nacional de Fortificação da Alimentação Complementar (ENFAC) ${ }^{[21]}$ realizado pelo Sistema Único de Saúde, Ministério da Saúde e Governo Federal nas cidades de Goiânia, Olinda, Porto Alegre e Rio Branco, entre 2012 e 2013, objetivou analisar a efetividade do uso de sachê de micronutrientes em pó, quando acrescentado ao alimento infantil, juntamente com ações de atenção básica à saúde e orientações a respeito de práticas alimentares saudáveis. O boletim do estudo revelou que $50 \%$ dos casos de anemia na infância provinham da deficiência de ferro. Os resultados mostraram, ainda, que a prevalência foi $38 \%$ menor nas crianças que receberam a fortificação. A deficiência de ferro no grupo que recebeu a intervenção foi $20 \%$ menor que no grupo controle, bem como a prevalência de deficiência de vitamina A, sendo esta 55\% menor entre as crianças que utilizaram os sachês ${ }^{[21]}$.

Costa et al.[22] em seus estudos realizados em Ilha Bela, litoral de São Paulo, mostraram que a prevalência da anemia ferropriva em crianças préescolares era, ainda, encontrada em 25,6\% da população amostrada. Surtos de Beribéri, doença provocada pela deficiência de tiamina (vitamina B1) e ocasionada por uma dieta pobre, pautada no consumo de mandioca, arroz e farinha de trigo, foram identificados entre 2006 e 2008 por Padilha et al.[23] no Maranhão. Além destes, há também diversos estudos que mostraram que a deficiência de vitaminas A, C, E e B12 ainda afetam a população brasileira ${ }^{[8,24]}$.

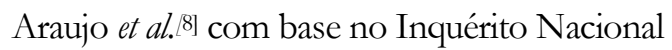
de Alimentação (INA), módulo da Pesquisa de Orçamentos Familiares (POF 2008 - 2009) identificaram ingestão inadequada de vitaminas D, E, A e $\mathrm{C}$, cálcio e magnésio por grande parte da população. Quanto ao ferro, este apresentou uma maior porcentagem de inadequação $(31,5 \%)$ entre as mulheres com idades entre 20 e 50 anos em comparação às mulheres mais velhas e aos homens. Os autores apontaram que as deficiências nutricionais não são, na maioria das vezes, originadas do consumo de quantidades insuficientes de alimentos, já que apenas $2,7 \%$ dos adultos brasileiros apresentaram baixo peso, mas sim frutos de uma alimentação de má qualidade, baixo consumo de cereais, frutas, leguminosas, hortaliças, leite e derivados e elevado consumo de alimentos processados e ultraprocessados, o que justifica a ingestão superior de sódio encontrada em grande parte desta mesma população. A fortificação dos alimentos, não foi também citada, pelos autores, como um fator que possa promover a adequação do consumo destes nutrientes, mas foi sim considerada um agravante, já que desencoraja os indivíduos a adotarem uma alimentação diversificada, saudável e equilibrada.

A deficiência de zinco acomete cerca de um terço da população mundial, notadamente em países desenvolvidos e em desenvolvimento, trazendo consequências drásticas à saúde humana, como aumento da mortalidade e morbidade das doenças com caráter infeccioso, problemas de crescimento, hipogonodismo, anorexia, danos neurológicos, entre outros ${ }^{[25]}$. 
Embora não existam no Brasil estudos nacionais que visem identificar a dimensão da carência desse micronutriente entre sua população, Beinner et al.[26] e Pedraza et al.[27]tendo como amostra crianças, estimaram que a deficiência de zinco afetava, respectivamente, $11,2 \%$ e $16,2 \%$ da população. Pedraza e Sales ${ }^{[25]}$ estimaram que cerca de $20,3 \%$ da população brasileira apresenta risco de consumo inadequado do nutriente e consideraram, ainda, como grupos de risco, os habitantes das periferias urbanas, os moradores de zonas rurais nas regiões Norte e Nordeste do Brasil, as crianças, as gestantes e os idosos de modo geral. Citam como principais medidas para combater o problema a educação nutricional, a fortificação dos alimentos, a suplementação focalizada em grupos populacionais vulneráveis, a biofortificação e o processamento caseiro dos alimentos (preparo), com o intuito de diminuir as quantidades de fitatos, que, quando presentes em um item alimentar, atrapalham a absorção do zinco.

A deficiência de iodo afeta, principalmente, as populações residentes em regiões montanhosas ou que sofrem inundações frequentes, já que nestes casos ocorre a remoção do iodo do solo, diminuindo o teor do nutriente no alimento. Esta deficiência ocasiona redução do crescimento e desenvolvimento das crianças, apatia, cretinismo, bócio, baixa estatura, retardo mental, danos à fala, audição e à coordenação motora, sendo apontada, mundialmente, como a causa mais comum e evitável de problemas ao desenvolvimento cerebral[28].

Embora presente em muitos alimentos de origem marinha, muitas vezes o consumo de alimentos fontes de iodo é prejudicado por diversas questões, principalmente as culturais, econômicas e ambientais, fazendo com que muitas crianças, gestantes e adultos no mundo todo não consigam suprir suas necessidades para este elemento[29,30].

No Brasil a principal medida utilizada para o combate à deficiência de iodo e seus distúrbios consiste na iodação do sal de cozinha, já que este é um ingrediente popular e frequentemente consumido[28]. Em locais cuja deficiência em questão apresente um maior grau de severidade, outras medidas deverão ser adotadas como a iodação da água e do óleo e a fortificação de outros alimentos ${ }^{[30] .}$

\section{Biofortificação de alimentos}

A biofortificação de alimentos é uma intervenção nutricional específica que busca aumentar o conteúdo de micronutrientes em alimentos por meio de práticas agronômicas ou melhoramento de plantas. Este pode se dar de modo convencional, com o cruzamento de vegetais da mesma espécie e seleção de genótipos que apresentem as características de interesse em maior grau, ou pode ocorrer através da engenharia genética, com a produção de cultivares transgênicos [31].

As práticas agronômicas incluem, principalmente, o uso de fertilizantes e técnicas de adubação do solo. Os micronutrientes mais estudados com o intuito de aumentar o seu teor nos alimentos de origem vegetal são o betacaroteno (pró-vitamina A), ferro e zinco, devido ao fato destas constituírem as principais carências de micronutrientes que afetam às populações humanas ${ }^{[32]}$.

A biofortificação de alimentos surgiu como uma das estratégias para que o consumo de nutrientes, principalmente micronutrientes, atingisse os valores mínimos recomendados, sobretudo pela parcela mais carente da população, que, consequentemente, mais sofre com os déficits nutricionais. Para tanto, a biofortificação têm como alvo os alimentos básicos como a mandioca, o milho, a batata-doce, a abóbora, o arroz, o feijão e o trigo. Outras estratégias empregadas com o intuito de suprir déficits de micronutrientes são a fortificação de alimentos, que ocorre durante $\mathrm{o}$ processamento do alimento e a criação de suplementos comerciais ${ }^{[31,32]}$.

Assim, como diversas outras medidas para garantia da SAN, a biofortificação deve ser controlada, fiscalizada, ter sua eficácia comprovada e deve receber e fornecer suporte para outras medidas conjuntas ${ }^{[33]}$.

Um fato importante é que, segundo Moraes $e t$ al.[34], o baixo teor de micronutrientes nos alimentos convencionais se deve ao melhoramento vegetal que visa apenas o ganho em produtividade das culturas sem considerar a qualidade nutricional dos itens alimentares. De qualquer forma, para conseguir-se manter a acessibilidade aos alimentos biofortificados, devido aos custos, estas variedades de vegetais deveriam aliar algum tipo de mecanismo de resistência ou manutenção da produtividade. Além disso, a fim de garantir a SAN, devemos pensar nos coadjuvantes que serão utilizados 
no cultivo destes alimentos, reduzindo o uso de defensivos químicos, incentivando o cultivo orgânico e fornecendo mudas capazes de serem cultivadas pelos pequenos produtores locais. Dessa forma, a biofortificação promoveria benefícios tanto para os agricultores familiares quanto para os compradores destes alimentos ${ }^{[34]}$.

Segundo Bouis et al. ${ }^{31]}$, o sucesso da biofortificação também dependeria da abordagem e atenção dada a três questões importantes:

- Seria viável, por meio do melhoramento convencional, atingir a concentração de micronutrientes necessária para que fosse possível notar diferenças significativas na condição nutricional do alimento?

- A absorção e a biodisponibilidade dos nutrientes adicionados se dariam em níveis suficientes, quando os alimentos fossem consumidos em condições controladas?

- Os produtos biofortificados seriam aceitos pelos produtores e consumidores e estes seriam capazes de produzi-los ou consumi-los em quantidades suficientes?

\section{Tipos de Biofortificação}

Como já mencionado, a biofortificação visa a obtenção de variedades melhoradas que apresentem maior teor de vitaminas e minerais na parte comestível dos alimentos, passando a considerar a composição nutricional e não somente os ganhos em produtividade ${ }^{[35]}$.

A técnica de biofortificação consiste no enriquecimento nutricional dos alimentos no campo, durante seu processo produtivo. Isso pode ser feito basicamente de duas maneiras: pelo melhoramento genético das culturas (convencional ou transgenia), o qual recebe o nome de biofortificação genética ou através do manejo da mesma, especialmente a partir da adubação, sendo está última técnica denominada biofortificação agronômica ${ }^{[36]}$.

\section{Biofortificação genética: a adoção do método de transgenia e convencional}

A biofortificação genética tem se mostrado como um caminho promissor para melhorar os teores de nutrientes e vitaminas nos alimentos de origem vegetal. Essa prática prioriza o desenvolvimento de cultivares que combinem níveis mais elevados de micronutrientes e vitaminas essenciais sem, contudo, alterar seu desempenho agronômico[37].

A modificação genética fundamenta-se na manipulação da constituição dos genes de um organismo vivo por eliminação, modificação ou adição de cópias de genes específicos, muitas vezes de outros organismos, por meio de técnicas de biologia molecular, tais como o DNA recombinante ou fusão celular. A engenharia genética permite que as plantas com melhor desempenho sejam selecionadas em uma única geração, assim os novos genes são introduzidos diretamente em cultivares locais. Também permite que características nutricionais sejam direcionadas para órgãos específicos e que vários atributos possam ser combinados na mesma planta[38].

O método de transgenia é necessário quando não há variação genética do conteúdo de nutrientes entre variedades vegetais e, em alguns casos, é potencialmente vantajoso, comparado ao melhoramento convencional. O exemplo mais conhecido é o Golden Rice, o arroz que contém cerca de $37 \mu \mathrm{g} / \mathrm{g}$ de carotenoides, dos quais $31 \mu \mathrm{g} / \mathrm{g}$ são $\beta$ caroteno[33,40].

A biofortificação por melhoramento genético convencional ocorre por meio do cruzamento das plantas com melhor desempenho e seleção daquelas com características favoráveis ao longo de muitas gerações. No entanto, o melhoramento convencional é limitado a genes que são provenientes de plantas sexualmente compatíveis e requer longos programas para introduzir características em variedades adaptadas localmente[38].

No Brasil, grande parte das culturas do projeto de biofortificação é resultado de cruzamento de plantas da mesma espécie a partir de variedades que existem na natureza ${ }^{[41]}$. 


\section{Biofortificação agronômica}

A biofortificação agronômica tem sido utilizada como prática complementar para tornar as culturas vegetais ainda mais nutritivas. Essa técnica é baseada na aplicação de adubos minerais e na melhora da solubilização e mobilização dos mesmos. Sua viabilização depende de vários fatores, incluindo a composição do solo, mobilidade do mineral no solo e a capacidade da planta armazená-lo nas partes comestíveis ${ }^{[36,41]}$.

As técnicas que compreendem a aplicação da biofortificação agronômica são: adubação via solo, tratamento de sementes ou aplicação foliar. Outras práticas como a aplicação de biofertilizantes (inoculação com fungos micorrízicos), rotação de culturas e irrigação também são adotadas visando aumentar o teor de minerais nas culturas ${ }^{[42]}$.

A administração de fertilizantes é simples e de baixo custo, mas apresenta algumas complicações devido ao método de aplicação, a composição do solo, a mobilidade do mineral na planta e o local de acumulação. $\mathrm{O}$ uso de fertilizantes com iodo, selênio e zinco, minerais móveis no solo e em plantas, aumentam as concentrações destes minerais em cereais e leguminosas. Por outro lado, o uso de FeSO4 (sulfato ferroso) não é eficiente, pois o ferro tem uma mobilidade reduzida no solo. Deve-se atentar para o fato de que grandes quantidades de metais aplicados aos solos são prejudiciais para o crescimento das plantas. É importante considerar, ainda, que os fertilizantes muitas vezes são aplicados regularmente e, assim, tornam-se potencialmente prejudiciais ao meio ambiente ${ }^{[39,43]}$.

Embora ambos os aspectos da biofortificação sejam importantes, a biofortificação genética (convencional ou transgenia) representa um processo mais caro e de longo prazo, incluindo a qualidade nutricional dos alimentos como um dos objetivos do processo continuado de melhoria das culturas. Já a biofortificação agronômica é uma ferramenta mais barata, acessível e de implementação instantânea, modificando apenas o manejo da cultura, em especial a adubação[36].

Enquanto a biofortificação genética possibilita aumentar substancialmente a concentração de nutrientes minerais, pró-vitamina $\mathrm{A}$, betacaroteno e proteínas, por exemplo, a biofortificação agronômica visa, principalmente, o enriquecimento dos alimentos em relação aos teores de minerais, especialmente Fe e $\mathrm{Zn}{ }^{[36]}$.

\section{Alimentos biofortificados desenvolvidos}

Os alimentos biofortificados desenvolvidos no Brasil são: a mandioca, o milho, a batata doce e a abóbora com maiores teores de carotenoides, especificamente de $\beta$-caroteno (pró-vitamínico A); o arroz, o feijão, o trigo e o feijão-caupi com maiores frações de ferro e zinco; e produtos processados elaborados a partir de matérias-primas biofortificadas ${ }^{[33]}$.

A biofortificação no Brasil também possui outras metas, como, por exemplo, analisar $\mathrm{O}$ desempenho agronômico (produtividade e resistência a pragas/doenças); promover o melhoramento participativo dos alimentos, a retenção de nutrientes e a biodisponibilidade dos mesmos; verificar hábitos de consumo alimentar, além de averiguar as condições socioeconômicas e o estado nutricional das populações alvo[33].

Quanto ao melhoramento convencional, no mundo foram desenvolvidos milheto, sorgo e lentilha com concentrações mais elevadas de ferro e zinco; batata com alto teor de ferro e banana com maiores proporções de compostos com atividade pró-vitamina $\mathrm{A}^{[41]}$.

No Brasil, a maioria das culturas desenvolvidas em projetos de biofortificação são frutos do cruzamento de vegetais de mesma espécie, cujas variedades são encontradas na natureza. A Embrapa, em seu projeto Biofort, realiza pesquisas com milho, batata-doce, abóbora e mandioca enriquecendo-os em compostos pró-vitaminícos A e feijão-caupi, arroz, trigo e feijão com altos teores de ferro e zinco ${ }^{[41]}$. Dentre os projetos de biofortificação já elaborados e lançados encontram-se cultivares de mandioca de mesa, feijãocaupi e feijão comum, além de variedades de batata doce e milho[33].

O Projeto de Melhoramento de Mandioca para Biofortificação, proposto pela Embrapa Mandioca e Fruticultura Tropical, almejava aumentar os teores de $\beta$ caroteno nas raízes do vegetal em questão, além de reduzir os teores de ácido cianídrico, ofertar boa 
qualidade para o consumo de mesa e boas características agronômicas através do uso do método de melhoramento convencional[44]. Em 2005, surgiu a variedade BRS Gema de Ovo ideal para o consumo como farinha ou cozida e BRS Dourada com $4 \mu \mathrm{g}$ de $\beta$-caroteno/g nas raízes frescas ${ }^{[4,45]}$. Em 2009, desenvolveu-se a mandioca de mesa BRS Jari com cerca de $9 \mu \mathrm{g}$ de $\beta$-caroteno/g nas raízes frescas ${ }^{[46]}$.

O Centro Internacional de Melhoramento de Milho e Trigo (CIMMY'T), no México, desenvolveu variedades de milho QPM (Quality Protein Maize), com proteína de maior valor biológico quando comparado com o milho comum ${ }^{[4]}$. Estas variedades desenvolvidas apresentam maiores teores de lisina $(52 \mathrm{mg} / \mathrm{g}$ de proteína) e triptofano $(10 \mathrm{mg} / \mathrm{g}$ de proteína), já o milho comum apresenta em média $30 \mathrm{mg}$ de lisina/g de proteína e $7 \mathrm{mg}$ de triptofano/g de proteína ${ }^{[48]}$. Segundo a OMS a dose recomendada de consumo de lisina é de $48 \mathrm{mg} / \mathrm{g}$ proteína e de triptofano de $6,6 \mathrm{mg} / \mathrm{g}$ proteína para crianças (3 a 10 anos) ${ }^{[49]}$. Para adultos o recomendado é de $45 \mathrm{mg}$ de lisina/g proteína e de $6 \mathrm{mg}$ de triptofano/g proteína ${ }^{[49]}$. Estes são aminoácidos essenciais para os seres humanos e são adquiridos somente através da alimentação. O milho QPM, além de beneficiar a saúde humana, também auxilia na nutrição animal, já que, no Brasil, aproximadamente $70 \%$ do milho produzido é destinado para a produção de ração[50].

Existem também pesquisas que buscam aumentar o teor de proteína de culturas alimentares, como o milho, utilizando a técnica de adubação (biofortificação agronômica). Nesse método realiza-se a adubação com nitrogênio, elevando, assim, o teor proteico do vegetal. Todavia, o que geralmente ocorre é um aumento no teor de zeína do milho, que por ser uma proteína de baixo potencial nutricional, não proporciona melhora na qualidade proteica da cultura. É importante considerar, ainda, que uso desta técnica em milhos comuns aumenta a produtividade e o teor proteico, porém modifica os teores de aminoácidos essenciais. Já no milho QPM, quando aplicada a adubação, ocorre uma manutenção ou elevação das concentrações dos aminoácidos lisina e triptofano ${ }^{[1]}$.

O Golden rice é um arroz que contém $37 \mu \mathrm{g} / \mathrm{g}$ carotenoides, sendo $31 \mu \mathrm{g} / \mathrm{g} \beta$-caroteno. Apesar do grão apresentar todos os genes essenciais para a síntese de compostos com atividade pró-vitamínica $A$, os arrozeiros convencionais produzem $\beta$-carotenos somente em tecidos verdes. O Golden rice foi, assim, a primeira cultura transgênica destinada a populações de baixa renda, não sendo exclusivamente voltado para os agricultores e empresas de pesticidas. $\mathrm{O}$ mesmo ocorreu com o tomate transgênico, que a partir do uso de genes bacterianos e de leveduras passou a apresentar elevadas concentrações de licopeno, carotenoide com alto potencial antioxidante ${ }^{[39,40] .}$

O uso da transgenia para biofortificação de alimentos já foi empregado também em outras culturas como na banana, produzindo frutos com maiores teores de pro-vitamínicos A e ferro e no sorgo, reduzindo $\mathrm{o}$ teor de fitatos (compostos antinutricionais), aumentando a concentração de carotenoides e melhorando seu perfil proteico ${ }^{[41]}$.

\section{Legislação e Regulamentação de alimentos biofortificados}

Não foram encontrados registros de legislação específica para biofortificação de alimentos no Brasil. Assim, optou-se por abordar a regulamentação disponível para alimentos fortificados e para as práticas de transgenia e melhoramento convencional, uma vez que estas são técnicas aplicadas na obtenção dos alimentos em questão.

A Portaria no 31, de 13 de janeiro de 1998, da Agencia Nacional de Vigilância Sanitária - ANVISA [52], tem como objetivo estabelecer a identidade e as características mínimas de qualidade para os alimentos adicionados de nutrientes essenciais. Nela, a ANVISA define alimentos fortificados como aqueles que sofrem adição de um ou mais nutrientes essenciais, naturais ou não, no alimento, com a finalidade de aumentar o seu valor nutritivo ou prevenir deficiências de um ou mais nutrientes na alimentação da população brasileira ou em grupos específicos. O enriquecimento pode ser feito, inclusive, para repor a quantidade de nutrientes perdida durante o processamento, permitindo-se adição de uma quantidade superior ao conteúdo normal, sob justificativa, sendo este alimento classificado como alimento restaurado. A Portaria determina que os Padrões de Identidade e Qualidade (PIC) do produto convencional devem ser seguidos, sendo que o enriquecimento não deve alterar as características da qualidade ${ }^{52]}$.

Os critérios estabelecidos para a adição de nutrientes visam regular a biodisponibilidade daqueles 
adicionados, a quantidade em níveis seguros, considerando também outras fontes presentes na dieta e a possibilidade de interação danosa entre um nutriente e os demais constituintes do alimento. No que tange a rotulagem, os alimentos simplesmente adicionados de nutrientes devem fornecer um mínimo de 7,5\% da IDR (Ingestão Diária Recomendada) de referência do nutriente para líquidos e 15\% da IDR para sólidos, sendo permitida a alegação "Fonte de (nutriente)". Os alimentos fortificados ou enriquecidos devem conter um mínimo de $15 \%$ da IDR de referência do nutriente para líquidos e 30\% da IDR para sólidos, estando autorizado o uso da alegação "Alto Teor ou Rico em (nutriente)". Ainda, no caso de enriquecimento de alimentos para Programas Institucionais, estes devem se basear em justificativas como: níveis baixos de ingestão do nutriente constatado por estudo epidemiológico; alimento selecionado como veículo do nutriente apresentar consumo significativo pela população que apresenta ou é vulnerável à carência; adição compatível com o déficit apresentado pela população afetada, a quem se destina o alimento[52].

Porém, no caso de um alimento que já possui quantidades superiores em micronutrientes como parte de sua fisiologia, como é o caso dos alimentos biofortificados, a Portaria acima não tem como atuar.

Uma das formas de se obter um alimento biofortificado é por meio do emprego da transgenia e de fato existem regulamentações para o processo de obtenção de itens alimentares transgênicos em geral. Contudo, não existe uma normatização específica para a biofortificação, com controles a serem adotados. A produção de transgênicos é regulamentada pelas resoluções da CTNBio (Comissão Técnica Nacional de Biossegurança) e pelo CNBS (Conselho Nacional de Biossegurança), além de leis e decretos existentes, a CTNBio é o órgão responsável por autorizar a realização de qualquer atividade que envolva organismos geneticamente modificados no Brasil. As legislações mais importantes para este tipo de alimento são:

- A Lei no 11.105 de 2005[53], que cria o CNBS, reestrutura a CTNBio e dispõe sobre a Política Nacional de Biossegurança (PNB). A lei de Biossegurança estabelece normas de segurança e mecanismos de fiscalização no uso das técnicas de engenharia genética na construção, cultivo, manipulação, transporte, comercialização, consumo, liberação e descarte de Organismos Geneticamente Modificados (OGMs), com o intuito de proteger a saúde do homem, dos animais e do meio ambiente.

- Decreto no 4.680 de 2003[54], que se refere à rotulagem de alimentos e ingredientes alimentares destinados ao consumo humano e animal, embalados, a granel ou in natura, que contenham ou sejam produzidos a partir de OGMs, com presença acima de 1\% no produto.

- Portaria no 2.658 de 2003[55], que alega que transgênicos devem trazer a letra " $T$ " envolta por um triângulo com o fundo amarelo, além da expressão "pode conter produto transgênico" ou "pode conter ingrediente produzido a partir de produto transgênico", no caso de origem vegetal. A existência de um Projeto de Lei que revoga essa Portaria está em discussão e, se aprovado, retira a obrigatoriedade da informação sobre o alimento ser ou não transgênico. Tal medida fere os direitos do consumidor a saber a origem dos alimentos consumidos.

\section{Histórico da Biofortificação e Pesquisas}

A origem dos trabalhos sobre biofortificação ocorreu em 1993, quando o jovem economista Howarth Bouis, do Instituto Internacional de Pesquisa em Políticas Alimentares (IFPRI), refletindo sobre os trabalhos de combate à fome oculta, conduzidos na época, perguntou-se: $e$ se as plantas pudessem fazerparte desse trabalho por nós? A partir do ocorrido, o pesquisador propôs a seleção de plantas visando não somente maior produção, mas também maiores teores de minerais e vitaminas na parte comestível dos vegetais. Assim originou-se a HarvestPlus, reconhecido programa internacional que promove e coordena ações de biofortificação de alimentos no mundo todo[5].

As atividades de pesquisa em biofortificação estão divididas entre os programas HarvestPlus, que conta com o apoio da Fundação Bill e Melinda Gates BMGF, Banco Mundial, entre outros e AgroSalud, contando com o apoio da Agência Canadense para o Desenvolvimento Internacional - CIDA. Estes programas têm como objetivo melhorar a qualidade nutricional das culturas alimentares consideradas básicas e fazer a distribuição de sementes enriquecidas em nutrientes entre os indivíduos que praticam agricultura de subsistência, buscando, dessa maneira, diminuir as deficiências nutricionais e garantir a segurança alimentar ${ }^{[42]}$. 
No Brasil, os trabalhos sobre biofortificação de alimentos tiveram início em meados dos anos 2000, quando a Embrapa consolidou uma rede de pesquisas que recebeu o nome de Rede BioFORT, vinculada ao HarvestPlus. Desde o seu início, a Rede BioFORT, coordenada pela Embrapa Agroindústria de Alimentos (Rio de Janeiro-RJ), concentrou seus esforços no melhoramento genético convencional das culturas, ou seja, biofortificação genética[ ${ }^{[36]}$.

Como parte dos esforços no combate à fome oculta foi criado, oficialmente em 2015, o Instituto de Estudos e Pesquisas em Fortificação de Alimentos e Combate à Fome Oculta (IPAF), na Universidade Federal de Viçosa (UFV), tendo a proposta de criação de um Instituto Nacional de Ciência e Tecnologia $(\text { INCT) })^{[36]}$.

Durante a trajetória da biofortificação, foram publicados alguns estudos que proporcionaram impacto relevante na evolução dessa técnica.

Welch et al. ${ }^{[57]}$ relataram aumento da biodisponibilidade de ferro e zinco para ratos alimentados com genótipos de feijão e arroz com maiores concentrações desses minerais. Em ensaios realizados com aves, utilizando um milho mutante low phytic acid (Lpa) 1, com reduzido teor de fitato (55-66\%), os animais apresentaram maior média de ganho de peso, além de maior conteúdo de fósforo e cálcio ósseo e sanguíneo, demonstrando o impacto positivo da redução do fitato.

Adams et al..$^{[58]}$ relataram médias de valores de absorção fracional de zinco em polenta preparada com o milho mutante (Lpa) (60\% de redução do teor de fitato) e milho padrão, respectivamente; utilizando marcação extrínseca em uma amostra de cinco adultos jovens sadios. Os autores concluíram que a substituição de grãos convencionais por grãos com baixo teor de fitato, no preparo de dietas à base de milho, está associada a um aumento expressivo na absorção de zinco.

Haas et al. ${ }^{[59]}$ realizaram um estudo duplo-cego com freiras de 10 conventos nas Filipinas, durante nove meses, utilizando arroz com alto teor de ferro $(3,21 \mathrm{mg}$ $\left.\mathrm{kg}^{-1} \mathrm{Fe}\right)$ e arroz controle $\left(0,57 \mathrm{mg} \mathrm{kg}^{-1} \mathrm{Fe}\right)$. Os resultados indicaram aumento da ferritina e hemoglobina, com melhor resposta para os indivíduos não-anêmicos limítrofes e que consumiram a maior parte do ferro oriunda do arroz biofortificado.

Halilu et al.600] estudaram a genética dos carotenoides para a biofortificação de grãos de milho tropicais adaptados, por compostos com atividade próvitamina A (PVA). A concentração de PVA foi determinada utilizando Cromatografia Líquida de Alta Eficiência (CLAE). Os resultados mostraram que o método de desenvolvimento hibrido apresentou impacto positivo na propagação de variedades de milho com alto conteúdo de pró-vitamina A. Concluiu-se que há amplo escopo para melhoria da biofortificação de milho com altos teores de substâncias pró-vitamínicas A e para o rendimento destes grãos.

\section{Controvérsias: Risco X Benefícios}

A questão do emprego da biotecnologia e da engenharia genética na agricultura e na produção de alimentos representa uma das principais controvérsias a ser discutida na atualidade, tanto em âmbitos econômicos, políticos e científicos quanto em âmbitos éticos, sendo defendida por alguns e condenada por outros $[7$.

De acordo com Moraes et al.[34], em 2050 a população mundial será constituída por, aproximadamente, 9 bilhões de pessoas, sendo que para suprir a demanda mundial por alimentos, haverá a necessidade de dobrar a produção agrícola mundial entre 1990 e 2030. Já os países em desenvolvimento deverão, neste mesmo período, ter sua produção agrícola aumentada de duas vezes e meia a três.

O cenário alimentar mundial é marcado pelo quadro de obesidade $x$ fome oculta, este último caracterizado pelas deficiências de micronutrientes específicos como ferro, iodo, zinco e vitamina A, afetando grande parte da população e constituindo-se em um dos principais problemas de saúde pública de diversos países, principalmente daqueles que ainda estão se desenvolvendo[ ${ }^{[61]}$.

Como principais causas para as carências de determinados nutrientes têm-se o elevado consumo de alimentos pobres em minerais e vitaminas em comparação àqueles nutricionalmente ricos; os baixos teores destes nutrientes no solo das áreas de cultivo agrícola; o processamento dos alimentos, que leva a 
uma diminuição em seu teor nutritivo; a presença de compostos antinutricionais, como os fitatos, que afetam a biodisponibilidade de determinados nutrientes, atrapalhando sua absorção; os maus hábitos alimentares das populações; a baixa prevalência do aleitamento materno; o estado nutricional inadequado de inúmeros indivíduos e a falta de diversificação da alimentação ${ }^{[8,24,34]}$.

Diante deste panorama marcado pela grande quantidade de pessoas expostas a situações de insegurança alimentar devido a carência de nutrientes específicos, os defensores da biofortificação citam que esta pode ser apontada como uma boa alternativa para a resolução do problema em questão, já que objetiva melhorar a qualidade nutricional dos alimentos através do melhoramento genético convencional ou uso de biotecnologia/transgenia e técnicas agronômicas, garantindo o acesso aos alimentos com qualidade nutricional superior a um maior número de pessoas.

Os principais argumentos utilizados pelos defensores residem no fato de que a existência de diversas variedades de uma mesma cultura possibilita que seja feita uma seleção das cultivares que apresentem uma maior capacidade de armazenar nutrientes em suas partes comestíveis, permitindo, assim, o cultivo de variedades nutricionalmente mais ricas[4]. Já as técnicas que adotam os princípios da transgenia visam ou aumentar a biodisponibilidade de alguns nutrientes, como o zinco e o ferro, ou incrementar a capacidade da planta absorver estes nutrientes do solo e armazená-los em seus constituintes comestíveis, permitindo, também, o cultivo de variedades com maior qualidade nutricional, sendo apontada como uma técnica capaz de agregar inúmeros benefícios à dieta e à saúde humana ${ }^{[4,62]}$.

Já biofortificação agronômica é realizada através da aplicação de fertilizantes nas culturas comestíveis, com o intuito de elevar o teor de determinados micronutrientes como zinco, ferro, iodo e selênio nestes alimentos ${ }^{[34]}$.

Pesquisas vêm, assim, sendo desenvolvidas nos últimos anos com o intuito de enriquecer os alimentos, aumentando seus teores de minerais, vitaminas e aminoácidos, sem entretanto, prejudicar sua produtividade agrícola. De acordo com Moraes et al. ${ }^{34]}$, estes fatos anteriormente citados fazem com que a biofortificação genética, bem como a agronômica sejam consideradas métodos viáveis para se combater o problema de fome oculta no mundo, trazendo inúmeros benefícios à segurança alimentar e nutricional da população mundial, em especial daqueles indivíduos que habitam as regiões de risco, cujos alimentos fortificados e a suplementação dietética não conseguem chegar de forma eficiente. Segundo Manos e Wilkinson[5] até 2015, aproximadamente 2,5 mil famílias tiveram acesso às sementes de culturas biofortificadas.

Embora muitos defendam o uso da biofortificação como estratégia para combater a fome, outros a associam a uma tragédia ambiental, capaz de tornar a agricultura dependente de empresas transnacionais e grandes latifundiários, o que levaria a uma piora da situação, já que favoreceria a concentração de renda e de terras [7].

Diversas organizações relacionadas à PNSAN citam que a adoção de culturas biofortificadas não é adequada para promover a SAN entre a população brasileira, identificando a ação como duvidosa[5]. Os diversos argumentos dos opositores à biofortificação são apresentados a seguir.

Manos e Wilkinson[5] em seus estudos a respeito das controvérsias acerca do tema biofortificação das culturas alimentares, identificaram que os principais problemas relacionados ao tema no Brasil e que trazem riscos à SAN da população são: os danos a agrobiodiversidade que as sementes biofortificadas podem trazer, limitando a diversidade alimentar; a complexidade do tema ao relacionar o melhoramento genético vegetal, as técnicas agronômicas e a transgenia ao aumento da biodisponibilidade de determinados nutrientes; a influência que as empresas internacionais produtoras das sementes biofortificadas exercem sobre a empresa pública brasileira de pesquisas agropecuárias (EMBRAPA); a associação das culturas biofortificadas com os organismos geneticamente modificados e seus possíveis riscos à saúde humana e o caráter duvidoso de que o emprego da biofortificação poderia resolver os problemas de fome oculta, quando na realidade procedimentos como a fortificação industrial de alimentos e a suplementação dietética são apontados por diversos especialistas como estratégias que não combatem as carências nutricionais das populações, já que desestimulam a adoção de hábitos alimentares saudáveis, diversificados, sustentáveis, equilibrados e 
culturalmente aceitos, podendo até mesmo agravar o problema.

De acordo com o Fórum Brasileiro de Soberania e Segurança Alimentar e Nutricional[63] o financiamento de pesquisas que visam instituir a biofortificação de alimentos no país vem sendo feito por meio de investimentos privados que não levam em conta os interesses e a participação da sociedade brasileira, ficando esta, aquém do que é decidido pelas grandes multinacionais.

As grandes empresas financiadoras da biofortificação, como a HarvestPlus, disseminam a ideia ilusória de que um alimento fortificado mediante processos biológicos apresente uma melhor qualidade nutricional devido à presença de uma maior concentração de determinado micronutriente. Entretanto, não deve ser esquecido que teores mais elevados de certo micronutriente não torna este alimento mais saudável ou mais "forte" nem que os alimentos não biofortificados são "nutricionalmente pobres" em comparação àqueles que sofreram o processo de biofortificação ${ }^{[64]}$.

Apesar da monocultura ser apontada desde os anos 40 como um dos principais fatores que levam à fome oculta e a padronização da alimentação, hoje em dia, ainda são propostas inúmeras iniciativas que não visam atuar sobre as causas do problema, mas sim apenas em seus desfechos, levando, até mesmo a uma superestimação do problema da fome oculta em âmbitos mundiais $[64,65,66,67,68]$.

As carências nutricionais são originárias da desnutrição, fome, pobreza e maus hábitos alimentares, não estando necessariamente ligadas a quantidade de um micronutriente em um alimento específico [69,70]. Deste modo, é mantido um ciclo vicioso já que a própria introdução da biofortificação sustenta o problema, colaborando com a concentração de renda e de terras, e apresentando-se interessante e lucrativa para os proprietários das sementes biofortificadas que oferecem uma solução artificial para a questão, caracterizando um sistema de retroalimentação ${ }^{[7,63]}$.

Os programas de biofortificação articulados à EMBRAPA vêm sendo introduzidos em diversos estados brasileiros sem consulta pública; sem diagnósticos nacionais que caracterizem o problema da carência de nutrientes e suas dimensões; sem estudos que objetivem identificar o risco da introdução destes alimentos na alimentação humana; sem a participação das equipes de saúde e dos movimentos sociais; sem regulamentações estatais para o uso e implementação destas sementes e sem estudos que visem identificar os impactos econômicos, nutricionais, sociais e ambientais destes alimentos quando introduzidos na sociedade e seu custo benefício[ ${ }^{[63,64]}$.

Outro fator que deve ser levado em consideração é a exposição da população a superdoses de determinados nutrientes, o que pode trazer consequências negativas à saúde, como efeitos tóxicos e aumento no risco de desenvolvimento de certos tipos de câncer, principalmente, nos grupos mais vulneráveis ${ }^{[11,72]}$. Além disso, o enriquecimento de um alimento por determinado nutriente pode promover a diminuição significativa dos teores de outros nutrientes. Deve-se também levar em consideração o fato de que a produção de biofortificados é centrada na utilização de agrotóxicos e fertilizantes, responsáveis por inúmeros danos ambientais, além de promover a redução biodiversidade alimentar ${ }^{[73,74,75]}$.

Os opositores à implementação da biofortificação defendem, assim, o consumo de "alimentos de verdade" (in natura e minimamente processados), adoção de práticas alimentares sustentáveis tanto no quesito econômico, quanto nos quesitos sociais e ambientais, dando importância aos aspectos regionalidade, agrobiodiversidade, cultura alimentar, diversificação da dieta, valorização das preparações tradicionais e adoção de uma alimentação equilibrada como principais formas de se combater a fome, a desnutrição, as carências nutricionais, bem como o problema do excesso de peso e suas inúmeras consequências, cada vez mais prevalentes em nossa sociedade $[8,24,63,64,76]$.

\section{Aspectos econômicos, sociais e políticos: a conexão com a biofortificação}

Desde 1940, Josué de Castro reconheceu que há distintas expressões e formas de conceituar a fome e, segundo ele, a monocultura é uma causa estrutural da monotonização alimentar, bem como da fome oculta[65,66],

É muito comum que instituições e iniciativas públicas e privadas busquem soluções que normalmente não interfiram nas causas do problema, 
focando apenas no desfecho da problemática. Entretanto, a discussão e a investigação das causas são processos fundamentais para a solução da questão. Caso semelhante ocorre com a estratégia denominada biofortificação, criada pelas grandes empresas para a manipulação das culturas alimentares, de modo a conseguir uma maior expressão de determinados micronutrientes[64].

O Instituto Internacional de Pesquisa em Política Alimentar - IFPRI publicou um relatório que trata e conceitua as vertentes que envolvem a biofortificação. Nesse documento há apenas um parágrafo que descreve as causas do problema e, ao longo do mesmo, pouco se menciona sobre as pressões das corporações transnacionais que controlam o sistema alimentar[63]. As políticas públicas envolvendo as problemáticas da biofortificação de alimentos são marcadas por conflitos de interesse entre as principais potencias mundiais, além das controvérsias envolvendo o sistema alimentar e nutricional.

As causas da fome oculta estão associadas ao baixo nível de renda de grande parte da população, às condições de moradia e alimentação, às desigualdades e à falta de saneamento básico. Não há como apontar uma única causa para o problema. O que se observa, muito pelo contrário, é que existem várias questões que, unidas, tornam-se as grandes responsáveis pela existência e manutenção das deficiências nutricionais entre a população mundial[5,8,14,24].

Ainda é restrito o número de pesquisas que identifique, com precisão, o contingente de pessoas que apresentam deficiências de nutrientes tanto no Brasil quanto no mundo. Órgãos importantes como a Organização das Nações Unidas para a Agricultura e Alimentação (FAO) e a OMS apresentam documentos que divergem quanto aos números de acometidos pelas carências, dificultando o estabelecimento de ações de soluções e melhorias para os problemas relacionados às deficiências nutricionais ${ }^{[63]}$.

Alguns documentos existentes apontam, ainda, várias sabotagens às práticas alimentares sustentáveis e saudáveis, movidas por forças econômicas e políticas que impõem modelos de produção e de consumo de alimentos estimulando a monotonização alimentar, como a biofortificação, prática que acaba impulsionando a produção e consumo de poucos itens alimentares, centrados naqueles cuja produção é controlada por grandes empresas em um sistema de monopolização/oligopolização e que, portanto, desestimulam a diversidade das dietas e a manutenção de hábitos saudáveis ${ }^{[67,77]}$.

Em relação aos fatores econômicos, o Brasil estabeleceu uma parceria entre a EMBRAPA e o HaverstPlus Challenge Programs, um programa multimilionário que conta com recursos financeiros de filantropos como a Fundação Bill e Melinda Gates, empresas como a Syngenta e organizações relacionadas com o setor privado que, alinhando os investimentos, interesses e negócios com o HaverstPlus, fizeram com que este se tornasse um líder mundial no desenvolvimento de grãos biofortificados. É importante considerar, ainda, que a inserção dos itens biofortificados no mercado brasileiro não contou com nenhum debate público ou controle social. Outro problema relevante é a ausência de mecanismos de regulamentação sobre os alimentos biofortificados, uma vez que estes itens estão chegando aos agricultores, às escolas e aos consumidores sem qualquer tipo de controle regulatório ${ }^{[63,64]}$.

Além destes, problemas que tangem a área da saúde pública vêm sendo questionados, como o fato dos itens biofortificados apresentarem teores aumentados de determinados micronutrientes e, em contrapartida, reduzidos teores de outro micronutriente ou macronutriente. Isso acontece, por exemplo, com vegetais manipulados para expressar uma maior concentração de ferro e que, consequentemente, acabam tendo o teor de fibras reduzido, fazendo com que muitas vezes haja a omissão do restante da composição nutricional destes alimentos que passaram por processos de biofortificação ${ }^{[63,73]}$.

É indispensável reconhecermos, portanto, a existência de um grande embate envolvendo a produção e o uso dos alimentos biofortificados e seus impactos na saúde humana, sociedade e meio ambiente.

\section{Biofortificação X Medidas Alternativas}

O programa BioFORT coordenado pela Embrapa está em desenvolvimento há mais de dez anos. Este busca reduzir a desnutrição e garantir a SAN através da biofortificação de alimentos. Neste projeto existem 14 unidades de pesquisa que estudam o melhoramento genético convencional de alimentos 
básicos presentes na dieta brasileira como: arroz, feijão, feijão caupi, mandioca, batata-doce, milho, abóbora e trigo, de modo a aumentar os teores de ferro, zinco e vitamina $A$, sem necessidade de mudança nos hábitos alimentares populacionais. Além das pesquisas acerca do enriquecimento nutricional dos alimentos, o programa visa, ainda, desenvolver tecnologias para a conservação dos micronutrientes. Desse modo, o BioFORT estabelece parcerias que objetivam desenvolver embalagens apropriadas destinadas aos alimentos processados. $\mathrm{O}$ projeto se preocupa desde o cultivo do alimento até a sua chegada na mesa do consumidor. É importante ressaltar que os novos cultivares, além de gerar benefícios nutricionais, devem proporcionar vantagens agronômicas e comerciais aos produtores ${ }^{[7]}$.

Como medidas alternativas à biofortificação no combate as carências nutricionais, existem aquelas estipuladas pelo Plano Nacional de Alimentação e Nutrição (PNAN), pelos Planos Nacionais e Estaduais de Segurança Alimentar e Nutricional e pelo Guia Alimentar para a População Brasileira, uma vez que este último propõe uma alimentação diversificada $\mathrm{e}$ saudável, relatando o direito que todos os indivíduos têm ao acesso à alimentação adequada e de qualidade.

O Ministério da Saúde possui, desse modo, diversas ações que objetivam combater as deficiências de micronutrientes na população brasileira, desde os programas citados que visam melhorar a qualidade da alimentação da população, incentivando a mudança de hábitos, até mesmo os programas de suplementação com megadose de vitamina A (para populações que apresentem risco), suplementos à base de sulfato ferroso e adição de iodo no sal de cozinha. A alimentação e a nutrição devem, assim, estar inseridas em conjuntos de ações integradas que visem à promoção da saúde e dos estilos de vida saudáveis e a prevenção das doenças ${ }^{[29] .}$

Uma das principais formas de combater a hipovitaminose A, a anemia ferropriva e outras deficiências e carências nutricionais são as ações de intervenção em educação nutricional, que visam educar a população a respeito da escolha dos alimentos, estimulando a adoção de uma alimentação diversificada e rica em alimentos fontes dos nutrientes deficientes na dieta, incentivando também a produção dos mesmos nas hortas comunitárias, escolares e caseiras e o consumo de alimentos regionais ${ }^{[29]}$.
O Guia Alimentar para a População Brasileira contém informações e recomendações para uma alimentação adequada e saudável de modo a acelerar o declínio da desnutrição, reverter o quadro de obesidade e de outras doenças crônicas e, consequentemente, promover a saúde a todos os brasileiros ${ }^{[7]}$.

De acordo com o enunciado da Política Nacional de Alimentação e Nutrição, a alimentação e nutrição integram os Direitos Humanos e são requisitos fundamentais para a promoção da saúde[79].

Para uma alimentação saudável é necessário um sistema alimentar social e ambientalmente sustentável, ou seja, o modo de produção e distribuição dos alimentos deve ser pautado no alcance da justiça social e respeito à integridade do meio ambiente. Além disso, deve-se seguir dez passos: fazer dos alimentos in natura ou minimamente processados a base da alimentação; utilizar óleos, gorduras, sal e açúcar em quantidades mínimas nos preparos culinários; limitar o consumo de alimentos processados; evitar o consumo de itens ultraprocessados; comer em locais apropriados e em companhia; adquirir alimentos em locais que comercializem grande variedade de alimentos in natura ou minimamente processados; pôr em prática e partilhar habilidades culinárias; planejar e redistribuir melhor o tempo para que a alimentação tenha seu espaço necessário; preferir realizar refeições fora do domićlíio em estabelecimentos que elaborem refeições feitas na hora aos invés de restaurantes que ofertem fast foods, e ser crítico quanto as informações veiculadas pela mídia e pelas propagandas ${ }^{[7]}$.

No Brasil, a aplicação de políticas públicas de erradicação da pobreza absoluta, redistribuição de renda, saneamento básico, educação e serviços de saúde, promoveu a redução da desnutrição entre a população. Além destes, outros programas foram desenvolvidos para controlar as carências específicas de micronutrientes em grupos vulneráveis da população brasileira (indígenas, quilombolas, crianças e mulheres habitantes de áreas vulneráveis) [76].

Dentre as intervenções já realizadas para melhoria do estado nutricional da população brasileira têm-se: a vigilância do estado nutricional da população, a promoção do aleitamento materno, a distribuição de refeições para crianças durante o período de aulas nas escolas públicas de ensino básico, a suplementação com ferro para crianças e gestantes, a suplementação com 
vitamina A para puérperas e crianças, a fortificação de alimentos, como, por exemplo, a farinha de trigo, entre outras medidas. Porém é importante ressaltar que as deficiências nutricionais ainda persistem em grupos populacionais específicos, sendo necessários programas que visem modificar os hábitos alimentares da população e promover a distribuição de renda de maneira mais equitativa entre os brasileiros, constituindo-se, estes, nos desafios prioritários a serem solucionados no campo da alimentação e nutrição brasileira[79].

\section{Considerações Finais}

A biofortificação é uma temática que ainda precisa ser debatida, seus aspectos e consequências devem ser melhores elucidados, bem como as propostas de solução para o problema das deficiências nutricionais devem ser pautadas nas dificuldades reais enfrentadas por pessoas que sofrem com a questão e que estão, na maioria das vezes, à margem da sociedade.

É evidente a necessidade de uma regulamentação específica para alimentos biofortificados e para o enriquecimento de alimentos a partir de meios agronômicos, a fim de controlar não só os teores de nutrientes e seus impactos na saúde, mas a maneira como tal procedimento é realizado, exigindo que se tenha o cuidado com a agrobiodiversidade e com o meio ambiente e permitindo a sustentabilidade da prática, de modo a evitar danos ao consumidor e aos produtores rurais. Espera-se que alguma atitude em relação a isso seja tomada, apesar dos entraves postos devido a questões políticas e econômicas, que já bloqueiam tantos outros assuntos polêmicos, que afetam diretamente a população.

No âmbito político, as questões que englobam temas como natureza e humanidade são visadas por diversos setores sociais e político-econômicos, cada qual defendendo seus interesses sociopolíticos. Não podemos esquecer que, apesar da biofortificação de alimentos apresentar aspectos positivos, como melhorar o teor de determinados micronutrientes em culturas alimentares básicas, ela ainda exibe diversas consequências negativas como o favorecimento da concentração de rendas e terras, possíveis danos à agrobiodiversidade, dependência em relação às sementes produzidas pelas empresas internacionais, riscos que organismos geneticamente modificados podem ocasionar à saúde humana e desestimulo à adoção de hábitos alimentares saudáveis.

É fundamental reconhecermos a existência de uma grande polêmica em relação à biofortificação de alimentos, sendo que o tema apresenta defensores e críticos, porém, é imprescindível considerarmos que as soluções mais eficientes para o combate aos problemas nutricionais da população devem ser focadas em suas causas, baseando-se, portanto, no incentivo ao consumo de alimentos in natura; na adoção de práticas alimentares sustentáveis tanto no quesito econômico, quanto nos quesitos sociais e ambientais; no consumo de alimentos e preparações regionais; na manutenção e preservação da agrobiodiversidade; na valorização da cultura alimentar; na diversificação da dieta e, sobretudo, na mudança dos hábitos alimentares e na melhora das condições socioeconômicas da população.

\section{REFERÊNCIAS}

[1] Nutti M. Entrevista: Marília Nutti. Aditivos Ingredientes [internet]. 2015 [acesso em 01 nov 2016]. Disponível em: http://aditivosingredientes.com.br/upload_arquivos/20160 1/2016010171360001453470224.pdf

[2] Long JK, Bänziger M, Smith ME. Diallel analysis of grain iron and zinc density in southern African - adapted maize inbreeds. Crop Sci. 2004;44:2019-2026.

[3] Welch RM, Graham RD. Breeding for micronutrients in staple food crops from a human nutrition perspective. J Exp Bot. 2004;55(396):353-364.

[4] White PJ, Broadley MR. Biofortifying crops with essential mineral elements. Trends Plant Sci. 2005;10(12):586-593.

[5] Manos MGL, Wilkinson J. Mapeamento de Controvérsias Socio-técnicas: o Caso da Biofortificação de Alimentos Básicos no Brasil. In: Atas do 5o Congresso Ibero-Americano em investigação qualitativa, Porto: CIAIQ; 2016. Porto: CIAIQ; 2016.

[6] Welch RM. Linkages between trace elements in food crops and human health. In: Alloway BJ. Micronutrient deficiencies in global crop production. Nova York: Springer; 2008.

[7] Vilarinho VB. Ciência e Tecnologia no Século XX GMO. Cadernos do CEIS20. 2009;15:1-46. 
[8] Araujo MC, Bezerra IN, Barbosa FS, Junger WL, Yokoo EM, Pereira RA, et al. Consumo de macronutrientes e ingestão inadequada de micronutrientes em adultos. Rev. Saúde Pública. 2013;47(1 Supl):177-189.

[9] Rossetti FX. Consumo alimentar, estado nutricional e percepção de segurança alimentar e nutricional entre estudantes de uma universidade pública [dissertação]. Piracicaba: Universidade de São Paulo; 2015.

[10] Rede de Alimentação e Nutrição do Sistema Único de Saúde. Deficiências de micronutrientes: um problema de saúde pública. Rede Nutri [internet]. 2016 [acesso em 15 nov 2016]. Disponível em: http:/ / ecos-redenutri.bvs.br

[11] WHO. Global prevalence of vitamin A deficiency in populations at risk 1995-2005. WHO Global Database on Vitamin A Deficiency. Geneva: World Health Organization; 2009.

[12] Teixeira RA. Deficiência de vitamina A e fatores associados em crianças e adolescentes em dois municípios do semiárido de Minas Gerais [tese]. Belo Horizonte: Universidade Federal de Minas Gerais; 2010.

[13] OMS. Diretriz: Suplementação de vitamina A em gestantes. Genebra: Organização Mundial da Saúde; 2013.

[14] Carvalho MC, Baracat ECE, Sgarbieri VC. Anemia ferropriva e anemia de doença crônica: distúrbios do metabolismo de ferro. Segur. Aliment. Nutr. 2006;13(2):5463.

[15] Amarante MK, Otigossa A, Sueiro AC, Oliveira CEC, Carvalho SRQ. Anemia ferropriva: uma visão atualizada. Biosaúde. 2015;17(1):34-45.

[16] OMS. Diretriz: Uso de formulações em pó de múltiplos micronutrientes para fortificação caseira de alimentos consumidos por bebês e crianças de $6-23$ meses de vida. Genebra: Organização Mundial da Saúde; 2013.

[17] Ministério da Saúde. Programa Nacional de Suplementação de Ferro: manual de condutas gerais. Brasília: Ministério da Saúde; 2013.

[18] Agência Nacional de Vigilância Sanitária. Resolução no 150, de 13 de abril de 2017. Revoga a Resolução no 344, de 13 de dezembro de 2002, que estabelece os requisitos para o enriquecimento de farinhas de trigo e de milho com ferro e ácido fólico. Diário Oficial da União. 13 abr 2017.
[19] Portal Anvisa. Regra para ácido fólico em farinhas é atualizada [internet]. 2017 [acesso em 27 set 2017]. Disponível em: http://portal.anvisa.gov.br

[20] Ministério da Saúde. Pesquisa Nacional de Demografia e Saúde da Criança e da Mulher - PNDS 2006: dimensões do processo reprodutivo e da saúde da criança. Brasília: Ministério da Saúde; 2009.

[21] Ministério da Saúde. Como prevenir a anemia e outras deficiências de nutrientes na infância. Boletim Enfac [internet]. 2014 [acesso em 27 set 2017]. Disponível em: http://189.28.128.100/dab/docs/portaldab/documentos/b oletim_enfac2014

[22] Costa JT, Bracco MM, Gomes PAP, Gurgel RQ. Prevalência de anemia em pré-escolares e resposta ao tratamento com suplementação de ferro. J Pediatr (Rio J). 2011;87(1):76-79.

[23] Padilha EM, Fujimori E, Borges ALV, Sato APS, Gomes MN, Branco MRFC, et al. Perfil epidemiológico do beribéri notificado de 2006 a 2008 no Estado do Maranhão, Brasil. Cad. Saúde Pública. 2011;27(3):449-459.

[24] Jaime PC. Síntese Teórica para TBL da aula PNAN: Atenção Nutricional - Carências de micronutrientes [síntese teórica para a disciplina de políticas públicas de alimentação e nutrição]. São Paulo: Universidade de São Paulo; 2016.

[25] Pedraza DF, Sales MC. Deficiência de zinco: diagnóstico, estimativas do Brasil e prevenção. Nutrire. 2015;40(3):397408.

[26] Beinner MA, Menezes MABC, Silva JBB, Amorim FR, Jansen AK, Lamounier JA. Plasma zinc and hair zinc levels, anthropometric status and food intake of children in a rural area of Brazil. Rev. Nutr. 2010;23(1):75-83.

[27] Pedraza DF, Rocha ACD, Queiroz EO, Sousa CPC. Estado nutricional relativo ao zinco de crianças que frequentam creches do estado da Paraíba. Rev. Nutr. 2011;24(4):539-552.

[28] Macedo MS, Teixeira RA, Bonomo E, Silva CAM da, Silva ME, Sakurai E, et al. Deficiência de iodo e fatores associados em lactentes e pré-escolares de um município do semiárido de Minas Gerais, Brasil, 2008. Cad. Saúde Pública. 2012;28(2):346-356.

[29] Brasil. Ministério da Saúde. Unicef. Cadernos de Atenção Básica: Carências de Micronutrientes. Brasilia: Ministério da Saúde; 2007. 
[30] Teixeira D, Calhau C, Pestana D, Vicente L, Graça P. Iodo - importância para a saúde e o papel da alimentação. Programa Nacional para a Promoção da Alimentação Saudável [internet]. 2014 [acesso em 20 nov 2016]. Disponível em: http:/ /ccipd.pt/wp-content/uploads/newsletter/15-1211/Iodo_saude_alimentacao_DGS_2014.pdf

[31] Bouis H, Low J, McEwan M. Tanumihardjo S. Biofortification: evidence and lessons learned linking agriculture and nutrition. Food and Agriculture Organization/World Health Organization [internet]. 2013 [acesso em 09 nov 2016]. Disponível em: http://www.fao.org/fileadmin/user_upload/agn/pdf/Biof ortification_paper.pdf

[32] Gonçalves ASF, Gonçalves WM, Silva KMJ, Oliveira RM. Uso da biofortificação vegetal: uma revisão. Cerrado Agrociências. 2015;6:75-87.

[33] Carvalho JLV, Nutti M. Biofortificação de produtos agrícolas para nutrição humana. In: Anais da $64^{a}$ Reunião da Sociedade Brasileira para o Progresso da Ciência; 2012; São Luiz, Maranhão: SBPC. São Luiz: SBPC; 2012.

[34] Moraes MF, Pascoalino JAL, Alves SJF, Nutti MR, Carvalho JLV. Biofortificação alternativa à segurança alimentar e nutricional. Informações Agronômicas. 2012;140:9-15.

[35] Graham RD, Welch RM, Saunders DA, Monasterio IO, Bouis HE, Bonierbale M, et al. Nutritious subsistence food systems. Adv. Agron. 2007;92:1-74.

[36] Vergütz L, Luz JMR da, Silva MCS, Kasuya MCM. Biofortificação de alimentos: saúde ao alcance de todos. Boletim Informativo da SBCS. 2016;42(2):20-23.

[37] Reis AR, Furlani Jr. E, Moraes MF, Melo SPM. Biofortificação agronômica com selênio no Brasil como estratégia para aumentar a qualidade dos produtos agrícolas. Brazilian Journal of Biosystems Engineering. 2014;8(2):128138.

[38] Johns T, Eyzaguirre PB. Biofortification, biodiversity and diet: a search for complementary applications against poverty and malnutrition. Food Policy. 2007;32:1-24.

[39] Hirschi KD. Nutrient Biofortification of Food Crops. Annu. Rev Nutr. 2009;29:401-421.

[40] Nestel P, Bouis HE, Meenaskhi JV, Pfeilffer W. Biofortification of staple food crops. J. Nutr. 2006;136(4):1064-1067.
[41] Saltzman A, Birol E, Bouis HE, Boy E, Moura FF, Islam $\mathrm{Y}$, et al. Biofortification: progress toward a more nourishing future. Global Food Security. 2013;2(1):9-17.

[42] Moraes MF, Nutti MR, Watanabe E, Carvalho JLV. Práticas agronômicas para aumentar o fornecimento de nutrientes e vitaminas nos produtos agrícolas alimentares. In: Anais do I Simpósio Brasileiro de Agropecuária Sustentável; 2009; Viçosa, Minas Gerais: UFV. Viçosa: UFV; 2009.

[43] Gómez-Galera S, Rojas E, Sudhakar D, Zhu C, Pelacho AM, Capell T, et al. Critical evaluation of strategies for mineral fortification of staple food crops. Transgenic Res. 2010;19(2):165-180.

[44] Fukuda WMG, Pereira MEC, Oliveira LA, Godoy RCB. BRS Dourada: mandioca de mesa com uso diversificado. Cruz das Almas: Embrapa Mandioca e Fruticultura Tropical; 2005.

[45] Fukuda WMG, Pereira MEC. BRS Gema de Ovo: mandioca de mesa biofortificada. Cruz das Almas: Embrapa Mandioca e Fruticultura Tropical; 2005.

[46] Fukuda WMG, Carvalho HWLD, Oliveira LAD, Oliveira IRD, Pinho JLN de, Santos VDS, et al. BRS Jari: nova variedade de mandioca para mesa com alto teor de betacaroteno nas raízes. Aracaju: Embrapa Tabuleiros Costeiros; Cruz das Almas: Embrapa mandioca e Fruticultura Tropical; 2009.

[47] Gunaratna NS, Groote H, Nestel P, Pixley KV, McCabe GP. A meta-analysis of community-based studies on quality protein maize. Food Policy. 2010;35: 202-210.

[48] Naves MMV, Silva MS, Cerqueira FM, Paes MCD. Avaliação química e biológica da proteína do grão em cultivares de milho de alta qualidade proteica. Pesquisa Agropecuária Tropical. 2004;34(1):1-8.

[49] WHO, FAO, United Nations University. Protein and amino acid requirements in human nutrition. Genebra: World Health Organization; 2007.

[50] Paes MCD. Aspectos físicos, químicos e tecnológicos do grão de milho. Embrapa milho e sorgo [internet]. 2006 [acesso em 12 nov 2016]. Disponível em: https://www.embrapa.br

[51] Bruulsema TW, Heffer P, Welch RM, Cakmak I, Moran K. Fertilizing Crops to Improve Human Health: a Scientific Review. Executive Summary. [internet]. 2012 [acesso em 10 nov 2016]. Disponível em: http:/ /www.fertilizer.org 
[52] Agência Nacional de Vigilância Sanitária. Portaria no 31, de 13 de janeiro de 1998. Dispõe sobre o regulamento técnico referente a alimentos adicionados de nutrientes essenciais. Diário Oficial da União. 31 jan. 1998.

[53] Brasil. Lei no 11.105, de 24 de março de 2005. Estabelece normas de segurança e mecanismos de fiscalização de atividades que envolvam organismos geneticamente modificados - OGM e seus derivados, cria o Conselho Nacional de Biossegurança - CNBS, reestrutura a Comissão Técnica Nacional de Biossegurança - CTNBio, dispõe sobre a Política Nacional de Biossegurança - PNB e dá outras providências. Diário Oficial da União. 28 mar 2005.

[54] Brasil. Decreto no 4.680, de 24 de abril de 2003. Regulamenta o direito à informação, assegurado pela Lei no 8.078, de 11 de setembro de 1990, quanto aos alimentos e ingredientes alimentares destinados ao consumo humano ou animal que contenham ou sejam produzidos a partir de organismos geneticamente modificados, sem prejuízo do cumprimento das demais normas aplicáveis. Diário Oficial da União. 25 abr 2003.

[55] Ministério da Justiça. Portaria no 2.658, de 22 de dezembro de 2003. Complementa o disposto no Regulamento Técnico para Rotulagem de Alimentos Embalados e tem o objetivo de definir a forma e as dimensões mínimas do símbolo que comporá a rotulagem tanto dos alimentos e ingredientes alimentares destinados ao consumo humano ou animal embalados como nos vendidos a granel ou in natura, que contenham ou sejam produzidos a partir de organismos geneticamente modificados. Diário Oficial da União. 26 dez 2003.

[56] Harvest Plus. Biofortification: The Nutrition Revolution Is Now [internet]. 2016 [acesso em 10 nov 2016]. Disponível em: http://www.harvestplus.org

[57] Welch RM, House AW, Beebe S, Senadhira D, Gregorio BG, Cheng Z. Testing iron and zinc bioavailability in genetically enriched beans (Phaseolus vulgaris L.) and rice (Oryza sativa L.) in rat model. Food and Nutrition Bulletin. 2000;21(4):428-433.

[58] Adams CL, Hambidge M, Raboy V, Dorsch JA, Sian L, Westcott JL, et al. Zinc absorption from a low-phytic acid maize. Am J Clin Nutr. 2002;76:556-559.

[59] Haas JD, Beard JL, Murray-Kolb LE, del Mundo AM, Felix A, Gregorio GB. Iron-biofortified rice improves the iron stores of nonanemic filipino women. J Nutr. 2005;135(12):2823-2830.
[60] Halilu AD, Ado SG, Aba DA, Usman IS. Genetics of carotenoids for provitamin A biofortification in tropicaladapted maize. The Crop Journal. 2016;4(4):313-322.

[61] Cozzolino SMF. Deficiências de minerais. Estudos Avançados. 2007;21(60):119-126.

[62] Grusak MA, Dellapenna D. Improving the nutriente composition of plants to enhance human nutrition and health. Annu Rev Plant Physiol Mol Biol. 1999;50:133-161.

[63] Fórum Brasileiro de Soberania e Segurança Alimentar e Nutricional. Biofortificação: as controvérsias e as ameaças a soberania e segurança alimentar e nutricional [internet]. 2016 [acesso em 20 nov 2016]. Disponível em: http://fbssan.org.br/wpcontent/plugins/downloadattachm ents/includes/download.php?id=1277

[64] Santos BF. A ação de organizações de combate à fome na iniciativa Scaling Up Nutrition [trabalho de conclusão de curso]. Brasília: Universidade de Brasília; 2015.

[65] Castro J. Geografia da fome. Rio de Janeiro: O Cruzeiro; 1946.

[66] Castro J. Geopolítica da fome. Rio de Janeiro: Casa do Estudante do Brasil; 1951.

[67] Welch RM, Graham RD. A new paradigm for world agriculture: meeting human needs: productive, sustainable, nutritious. Field Crops Research. 1999;60:1-10.

[68] Tilzey M. Natural areas, the whole countryside approach and sustainable agriculture. Land Use Policy. 2000;17:279294.

[69] Queiroz D, Paiva AA, Pedraza DF, Cunha MAL, Esteves GH, Luna JG, et al. Deficiência de vitamina A e fatores associados em crianças de áreas urbanas. Rev. Saúde Pública. 2013;47(2):248-256.

[70] Miglioni TC, Fonseca VM, Gomes Junior SC, Lira PIC, Batista Filho M. Deficiência de vitamina A em mães e filhos no Estado de Pernambuco. Ciênc. Saúde Coletiva. 2013;18(5):1427-1440.

[71] Druesne-Pecollo N, Latino-Martel P, Norat T, Barradon E, Bertrais S, Galan P, et al. Beta-carotene supplementation and câncer risk: a systematic review and metanalysis of randomized controlled trials. Int. J. Cancer. 2010;127(1):172184. 
[72] Zimmermann MB, Chassard C, Rohner F, N'goran EK, Nindjin C, Dostal A, et al. The effects of iron fortification on the gut microbiota in African children: a randomized controlled trial in Cote d'Ivoire. Am. J. Clin. Nutr. 2010;92(6):1406-15.

[73] Davis DR, Epp MD, Riordan HD. Changes in USDA food composition data for 43 garden crops, 1950 to 1999. J. Am. Coll. Nutr. 2004;23(6):669-82.

[74] Mäder P, Fliessbach A, Dubois D, Gunst L, Fried P, Niggli U. Soil fertility and biodiversity in organic farming. Science. 2002;296(5573):1694-1697.

[75] Carneiro FF, Rigotto RM, Augusto LGS, Friedrich K, Búrigo AC. Dossiê Abrasco: um alerta sobre os impactos dos agrotóxicos na saúde. Rio de Janeiro: EPSJV; 2015.

[76] Ministério da Saúde. Guia Alimentar para a População Brasileira. 2.ed. Brasillia: Ministério da Saúde; 2014.

[77] Gomes FS. Artificial mends to food systems. In: Dederichs-Bain B, Ramm WC. Food fortification: a technofix or a sustainable solution to fight hidden hunger? Bonn: Deutsche Welthungerhilfe \& Terre des Hommes; 2014. p. 57-60.

[78] Lanzetta P. Alimentos biofortificados buscam reduzir a desnutrição da população. Embrapa [internet]. 2015 [acesso em 04 nov 2016]. Disponível em: https://www.embrapa.br

[79] Ministério da Saúde. Política Nacional de Alimentação e Nutrição. Brasília: Ministério da Saúde; 2013. 